\title{
Nonconventional amide bond formation catalysis: programming enzyme specificity with substrate mimetics
}

F. Bordusa

\section{Correspondence}

F. Bordusa

Max-Planck Society, Research Unit

"Enzymology of Protein Folding"

W einbergweg 22

D-06120 Halle/Saale

Germany

Fax: +49-345-551-1972

E-mail: bordusa@ uni-leipzig.de

Research supported by the Deutsche Forschungsgemeinschaft (JA 559/9-1 and INK 23), and Fonds der

Chemischen Industrie, ASTA M edica

$A G$, and Fluka AG.

Presented at the XXVIII Annual Meeting of the Brazilian Society of Biochemistry and Molecular Biology, Caxambu, MG, Brasil, May 22-25, 1999

Received November 5, 1999 Accepted January 3, 2000
Max-Planck Society, Research Unit "Enzymology of Protein Folding", Halle/Saale, Germany

Department of Biochemistry, Faculty of Biosciences,

Pharmacy and Psychology, U niversity of Leipzig, Leipzig, Germany

\section{Abstract}

This article reports on the design and characteristics of substrate mimetics in protease-catalyzed reactions. Firstly, the basis of protease-catalyzed peptide synthesis and the general advantages of substrate mimetics over common acyl donor components are described. The binding behavior of these artificial substrates and the mechanism of catalysis are further discussed on the basis of hydrolysis, acyl transfer, protein-ligand docking, and molecular dynamics studies on the trypsin model. The general validity of the substrate mimetic concept is illustrated by the expansion of this strategy to trypsin-like, glutamic acid-specific, and hydrophobic amino acid-specific proteases. Finally, opportunities for the combination of the substrate mimetic strategy with the chemical solid-phase peptide synthesis and the use of substrate mimetics for non-peptide organic amide synthesis are presented.

\section{Introduction}

In addition to the natural function of enzymes, their capability of catalyzing selective transformations also makes these biomolecules useful catalysts in synthetic organic chemistry. The enzyme of choice for the synthesis of peptides or proteins should be the ribosomal peptidyl transferase or, alternatively, the microbial nonribosomal multienzyme complexes. Both enzyme systems catalyze the synthesis of peptides and proteins in vivo with remarkable properties, i.e., high reaction rates, independence of the sidechain functions of the amino acids, mild reaction conditions using water as solvent, regio- and stereospecificity and, therefore, absence of racemization and no need for side-chain protection. The synthetic use of these biocatalytic approaches would indisputably facilitate the chemical synthesis of peptides which often suffers from problems such as racemization, time-consuming sidechain protection and deprotection strategies, poor solubility of protected peptide fragments, and length limitation. Unfortunately, the ribosomal enzyme system essentially requires a coordinated action of numerous low and high molecular weight factors for their catalytic activity which restricts their use in vitro for peptide synthesis from being easily and universally applicable (1). In the same way, the nonribosomal poly-or multienzymes which are involved in the biosynthesis of 
peptide antibiotics (2) are only limited to special purposes. Owing to the prediction of the general reversibility of chemical reactions by van't Hoff, only the reverse hydrolysis potential of proteases can alternatively be used to catalyze peptide bond formation. Like the original in vivo pathways of peptide synthesis, the protease-mediated peptide bond formation occurs with a comparable high degree of regio- and stereospecificity and, furthermore, reactions can also be performed in aqueous solvents under mild reaction conditions (3-5). However, as already indicated by the natural function of these enzymes for the cleavage of peptides and proteins, proteases do not act as perfect acyl transferases. The amidase activity of proteases which may cause undesirable proteolytic cleavages of the peptide chain formed and the limited substrate specificities of these enzymes which restricts the amino acid residues accepted for coupling are the major disadvantages of this approach. This article reviews the strategy of substrate mimetics as a general and powerful concept for programming the substrate specificity of proteases in the direction of a more flexible utility of these enzymes as biocatalysts in synthetic organic chemistry. Furthermore, enzymological insights at the molecular level in binding of substrate mimetics and kinetics of substrate mimetic-mediated protease reactions are described.

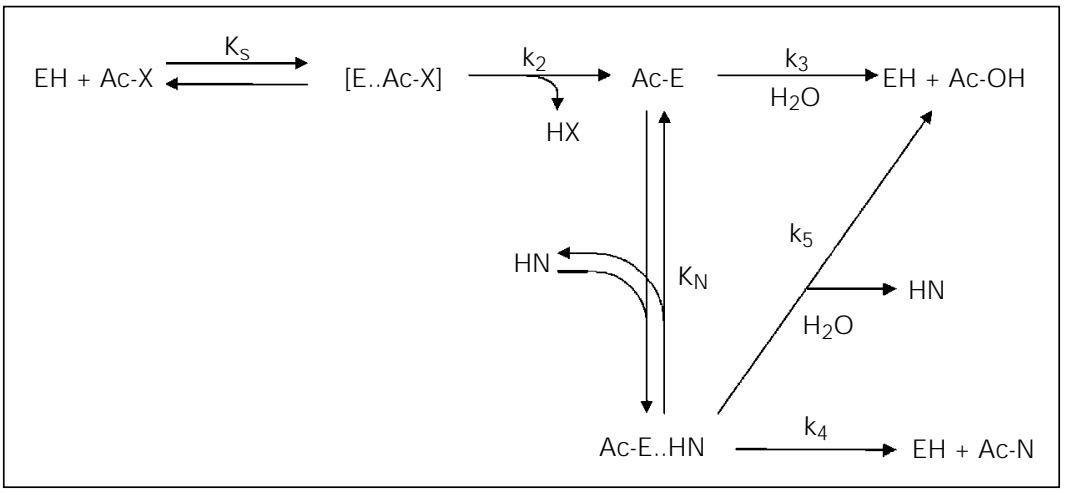

Figure 1 - Kinetic model of a protease-catalyzed acyl transfer reaction. EH, Free enzyme; Ac$\mathrm{X}$, acyl donor; $\mathrm{HX}$, leaving group; Ac-E, acyl enzyme complex; $\mathrm{Ac}-\mathrm{OH}$, hydrolysis product; $\mathrm{HN}$, acyl acceptor; Ac-N, aminolysis product.

\section{Basis of protease-catalyzed peptide bond formation}

Generally, within the methods of protease-catalyzed peptide bond formation two basic strategies are distinguished, i.e., a thermodynamic and a kinetically controlled approach (6). The thermodynamic strategy represents the direct reversal of catalytic proteolysis and ends with a true equilibrium. Since this equilibrium-controlled approach is an endergonic process, manipulation of reaction conditions is essentially required to shift the equilibrium in the direction of the peptide product to increase the yield of the coupling reaction (7). In the kinetically controlled approach the serine or cysteine protease acts as a transferase catalyzing the acyl transfer from a substrate ester to an $N^{\alpha_{-}}$ unprotected amino acid or peptide derivative forming a new peptide bond. Compared to the thermodynamic strategy, the kinetically controlled approach is faster and usually allows a more efficient manipulation resulting in higher product yields. Figure 1 illustrates the general kinetic scheme of the kinetically controlled peptide bond formation. Initially, the binding of the substrate ester to the enzyme leads to a tetrahedral enzyme-substrate complex which collapses to the covalent acyl enzyme intermediate Ac-E. In the common course of protease action, the deacylation step is initiated by the attack of water finally resulting in the hydrolysis product Ac-OH and the free enzyme EH. The value of the kinetic approach for peptide synthesis is based on the fact that Ac-E can be intercepted not only by water, but also by nucleophiles acting as amino components in peptide synthesis. The significant enhancement of esterase versus amidase activity of such acyl enzyme-forming proteases leads to a high rate of peptide bond formation while the rate of proteolysis of the newly formed amide bond is lower. Consequently, these different rates lead to a temporary accumulation of the peptide product. In 
contrast to proteolytic cleavage, the proteasecatalyzed formation of a peptide bond is a two-substrate reaction (Figure 1). While the acyl donor binds to the S-subsite of the enzyme the amino component acting as an acyl acceptor interacts with the S'-binding site (subsite notation according to Ref. 8). The efficiency of the nucleophilic attack of the added amino component depends on an optimal binding in the $S^{\prime}$-subsite region of the protease. Since the S'-subsite specificity is an individual parameter for each enzyme, the efficiency of peptide bond formation and, thus, the synthetic utility as a biocatalyst differs from enzyme to enzyme and can be predicted by subsite mapping based on acyl transfer studies (2).

\section{Characteristics of protease-catalyzed kinetically controlled peptide synthesis}

The synthetic value of proteases as biocatalysts for peptide synthesis is based on a number of advantages of this approach over chemical synthesis methods. The extraordinarily mild reaction conditions, the possibility of using immobilized enzyme technology with catalyst recovery, the scope for industrial scale-up, and especially the high degree of regio- and stereospecificity, which guarantees freedom from racemization and from the need for side-chain protection, represent the major advantages of the protease approach. Because of these characteristics, in particular the protease-catalyzed condensation of side-chain unprotected peptide fragments represents a promising method for the synthesis of larger peptides and even of proteins $(9,10)$.

On the other hand, the classical protease approach used so far has several serious drawbacks: i) Since proteases do not function as perfect acyl transferases, these enzymes catalyze both the acyl transfer to amino components and, simultaneously, the hydrolysis of the acyl donor components (cf. Figure 1). Thus, the resulting hydrolysis prod- uct, which possesses a very low acylation potential, lowers the yield of the desired peptide product. ii) Most important, the specificities of the available proteases do not enable all proteinogenic sequences to be assembled, and non-proteinogenic amino acids usually are not acceptable substrates of these enzymes. Therefore, only the coupling of peptide sequences closely related to preferred amino acid residues is of practical relevance. iii) In the synthesis of longer peptides, there is a permanent risk of proteolytic side reactions both of the starting peptide fragments and the peptide product formed.

As a general result of these drawbacks, the protease approach requires a very careful planning and often time-consuming optimization of the reaction conditions which usually restricts the use of proteases. Therefore, a more flexible use of proteases as biocatalysts for peptide synthesis essentially needs the development of efficient strategies to overcome the causes of the mentioned limitations. Besides the engineering of the reaction media (11-14) or the enzyme itself (1518), the application of substrate mimetics as acyl donor components particularly appears to be a promising strategy achieving irreversible coupling of nonspecific acyl components.

\section{Mechanism of protease-catalyzed hydrolysis of substrate mimetics}

The structural requirement for a protease substrate is the presence of specific amino acids in the acyl moiety, for example Arg or Lys in the case of trypsin. However, it has been shown that also the leaving group has a certain influence on the activity of the protease. Therefore, an extension of the enzyme-substrate interactions toward the S'subsites is useful to gain still higher specificities (19-22). A very different approach is the design of a new class of substrates, originally developed as time-dependent irreversible inhibitors of trypsin and trypsin-like 
proteases that have a nonspecific acyl residue, but bear a highly specific leaving group. The first examples of such inhibitors were 4amidino- and 4-guanidinophenyl esters (OGp), at that time termed as inverse esters, which were found to be hydrolyzed by these proteases nearly independent of their acyl moieties $(23,24)$. Although this fact was first reported in 1973 (23), only little was known about the basic mechanism of the hydrolysis of these esters. On the basis of the familiar model of substrate recognition (Figure 2), conventional ester substrates bind with their acyl residue to the S-binding site of the enzyme having the leaving group at the S'subsite and the scissile ester bond between attacked by the active amino acid residue of the enzyme (Ser195 in the case of trypsin). In contrast, applying the same binding principles to inverse esters leads to a catalytically unproductive binding as indicated by Figure 2. The acyl residue would bind at the S-subsite, but the scissile ester bond would be far away from the active site and could not be attacked by Ser195. Hence, hydrolysis would not occur and, therefore, cannot be

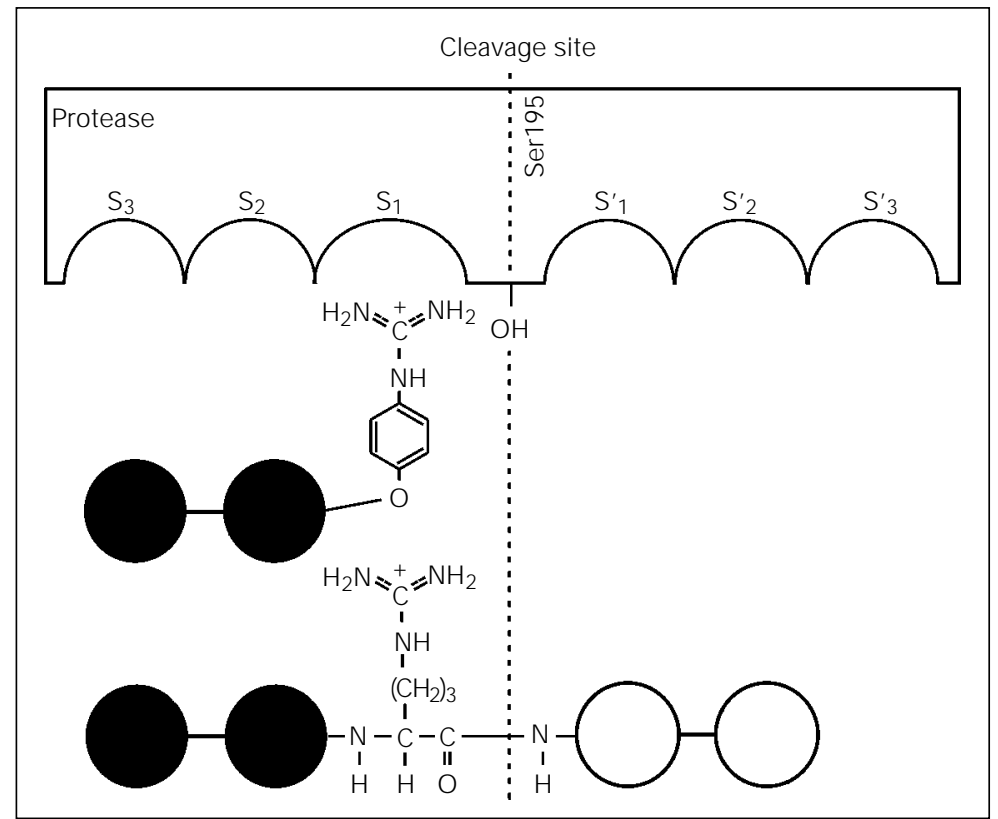

Figure 2 - Schematic comparison of the binding of a peptide-4-guanidinophenyl ester and a common peptide substrate to the active site of trypsin based on the ideas of the conventional binding model of proteases (nomenclature according to Ref. 8). explained on the basis of the conventional model of substrate hydrolysis.

Undisputably, the elucidation and understanding of the hydrolysis mechanism of substrate mimetics need a detailed knowledge of the enzyme-substrate interactions. X-ray structures of enzyme-substrate complexes would be helpful but are not easily accessible due to the low intrinsic stability of these esters. Alternatively, we have used a non-conventional combination of experimental and theoretical approaches, i.e., hydrolysis and aminolysis kinetics, protein-ligand dockings, and molecular dynamics studies, utilizing trypsin as a model catalyst to demystify the mechanism of substrate mimetic hydrolysis (25). Table 1 indicates kinetic data for the trypsin-catalyzed hydrolysis of a library of Boc-Xaa-OGp substrates derived from both L- and D-amino acids. Although all substrates were hydrolyzed by the enzyme despite the lacking trypsin-specific acyl moieties, the table shows differences in the second order rate constants $k_{\text {cat }} /$ $K_{\mathrm{M}}$ of more than three orders of magnitude. On the basis of linear free energy relationships, the values for $k_{\text {cat }} / K_{\mathrm{M}}$ should be equally reflected by the calculated binding energies. Therefore, the same substrate library was computationally docked towards trypsin. The results of these studies reveal similar specificity data and, therefore, lead to a good correlation between the calculated binding energies and the values for $k_{\mathrm{cat}} / K_{\mathrm{M}}$ (Figure $3)$. The splitting up of the data into two sets is based on the distinct lower $k_{\text {cat }}$-values found for the D-configured substrates which cannot be simulated by the theoretical docking approach. Because of the correlation between experimentally observed and theoretically calculated specificities the enzymesubstrate complexes were analyzed in detail. A representative enzyme-substrate complex of trypsin and Boc-L-Ala-OGp was superimposed on the trypsin-BPTI complex (26) which was found by X-ray structure analysis. Indicated by the trypsin-Boc-L-Ala-OGp 
complex, the OGp-group binds to the $\mathrm{S}_{1-}$ binding pocket of the enzyme like the sitespecific Lys side chain of BPTI, as already postulated in Figure 2. Because of this novel binding mode we introduced the denomination substrate mimetics for this type of artificial protease substrates (27). Comparison of both complexes shows that despite of the OGp-binding at the $\mathrm{S}_{1}$-position of the enzyme the scissile ester bond of Boc-L-AlaOGp is exactly located at the same position as the scissile peptide bond between $\mathrm{P}_{1}$ Lys 15 and $\mathrm{P}_{1}$ '-Ala16 in the trypsin-BPTI complex. Interestingly, this arrangement results from a reverse binding of the acyl residue of Boc-L-Ala-OGp which, contrary to the acyl residue of BPTI (Pro13-Cys14Lys15), binds to the S'-subsite of trypsin instead of binding to the enzyme's S-subsite. Due to the correlation of data for hydrolysis and computational docking, this reverse recognition should further result in the formation of an acyl enzyme intermediate having the acyl residue at the S'-subsite. The following deacylation step, however, needs an unoccupied S'-subsite. Thus, water can attack from the S'-side without hindrance. Hence, prior to the deacylation step, the acyl residue has to flip to the S-subsite of the enzyme. Because of this additional intermediate of catalysis, the kinetic model has to be extended by a rearrangement step between the two acyl enzyme species E-Ac and Ac-E characterized by the equilibrium constant $K_{\mathrm{R}}$ (Figure 4). The experimental findings show (cf. Table 1) that D-configured substrates indeed exhibit lower $k_{\text {cat }}$-values which might be related to lower $K_{\mathrm{R}}$-values. The high catalytic efficiency for L-configured substrates could be explained by significantly higher rearrangement equilibrium constants. In order to study the dynamic behavior of various acyl residues, their time-dependent occupancies in the S- and S'-subsites for Boc-LAla- and Boc-D-Ala-trypsin have been calculated. Both the rearrangement step itself and the preferred binding of D-configured acyl residues to the S'-subsite and L-configured counterparts to the S-subsite could be confirmed (25). For the experimental investigation of the S'-subsite accessibility, aminolysis studies are suitable. By their S'-specific binding, peptide nucleophiles should be able to push aside the acyl residue more efficiently from the S'-region than water.

Table 1 - Steady-state kinetic parameters for the hydrolysis of Boc-Xaa-OGp by trypsin (25).

Conditions: 25 mM MOPS-buffer, pH 7.6, 100 $\mathrm{mM} \mathrm{NaCl}, 5 \mathrm{mM} \mathrm{CaCl} 2,25^{\circ} \mathrm{C}$; errors are less than $15 \%$.

\begin{tabular}{lccc}
\hline Substrate & $\begin{array}{c}\mathrm{K}_{\mathrm{M}} \\
(\mathrm{mM})\end{array}$ & $\begin{array}{c}\mathrm{k}_{\text {cat }} \\
\left(\mathrm{s}^{-1}\right)\end{array}$ & $\begin{array}{c}\mathrm{K}_{\text {cat }} / \mathrm{K}_{\mathrm{M}} \\
\left(\mathrm{M}^{-1} \mathrm{~s}^{-1}\right)\end{array}$ \\
\hline Boc-L-Ala-OGp & 0.206 & 32.4 & $1.6 \times 10^{5}$ \\
Boc-D-Ala-OGp & 0.161 & 0.61 & $3.8 \times 10^{3}$ \\
Boc-Gly-OGp & 0.087 & 23.5 & $2.7 \times 10^{5}$ \\
Boc-L-Leu-OGp & 0.146 & 38.8 & $2.7 \times 10^{5}$ \\
Boc-D-Leu-OGp & 0.035 & 0.85 & $2.5 \times 10^{4}$ \\
Boc-L-Gln-OGp & 0.239 & 35.2 & $1.5 \times 10^{5}$ \\
Boc-D-Gln-OGp & 0.071 & 0.68 & $9.6 \times 10^{3}$ \\
Boc-L-Phe-OGp & 0.211 & 66.1 & $3.1 \times 10^{5}$ \\
Boc-D-Phe-OGp & 0.249 & 9.0 & $3.6 \times 10^{4}$ \\
Boc-L-Glu-OGp & 0.071 & 5.5 & $7.6 \times 10^{4}$ \\
Boc-D-Glu-OGp & 0.039 & 0.43 & $1.1 \times 10^{4}$ \\
Boc-L-Lys-OGp & 0.107 & 270 & $2.5 \times 10^{6}$ \\
Boc-D-Lys-OGp & 0.314 & 15.7 & $5.0 \times 10^{4}$
\end{tabular}

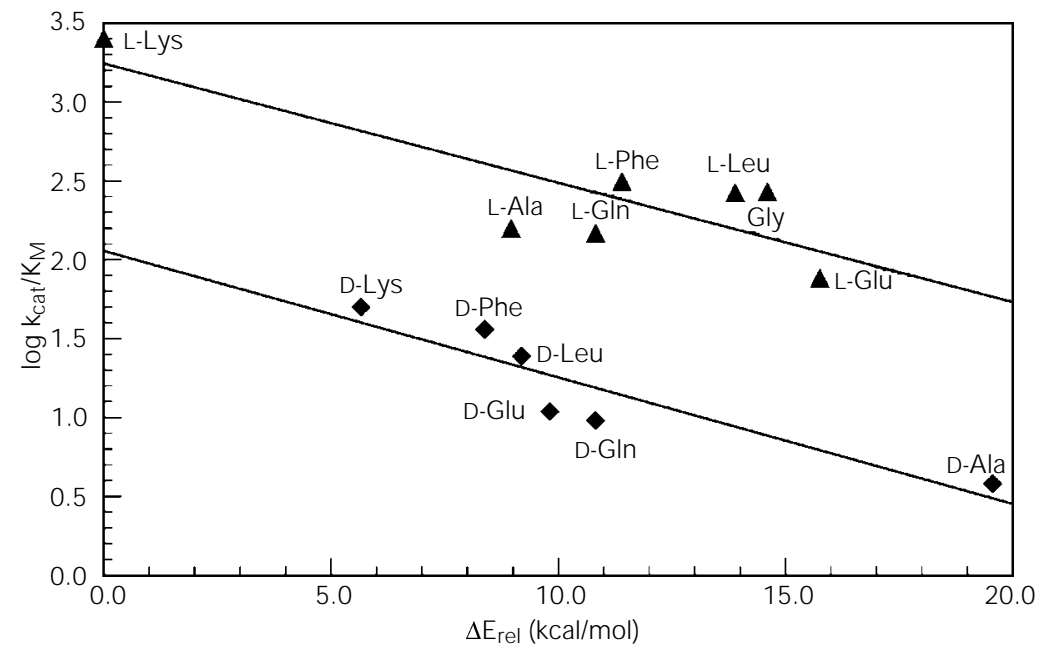

Figure 3 - Correlation between the calculated binding energies of the most stable productive complexes of Boc-Xaa-OGp and trypsin and the specificity constants of the hydrolysis reaction (25). The correlation coefficients are $\mathrm{R}=-0.84$ for the L-series including Gly (triangles) and $R=-0.91$ (lozenges) for the $D$-series. 
Therefore, the aminolysis of acyl enzymes bearing the acyl moiety in S' should occur at higher rates than their hydrolysis. Consequently, the ratio of hydrolysis to aminolysis, as given by the partition value $p$, should be low for D-configured acyl residues and higher for their L-configured counterparts. The more their $K_{\mathrm{R}}$-values differ, the more their $p$-values should vary. Indeed, the experimental results show dramatically lower $p$-values for the deacylation of Bz-D-Alathan for Bz-L-Ala-trypsin. In the case of the L-Leu and D-Leu analogs, the same situation occurs but with lower differences in the $p$ values corresponding to the smaller differences in the hydrolysis kinetic constants (Figure 5). Consequently, the experimental re- sults support this unique catalysis mechanism for substrate mimetics too.

\section{Substrate mimetics for Arg-specific proteases}

Beside proposing a unique catalysis mechanism for substrate mimetics, the hydrolysis and analytical acyl transfer experiments also indicate the general ability of 4-guanidinophenyl esters to act as acyl donors in trypsin-catalyzed peptide syntheses. This assumption was confirmed for the first time in 1991 by model syntheses of short peptides using various nonspecific $N^{\alpha}$-protected amino acid-4-guanidinophenyl esters as acyl donors and several amino acid amides as acyl
Figure 5 - Partition values $p$ for the aminolysis of Boc-D/L-AlaOGp and Boc-D/L-Leu-OGp compared to the common substrate Bz-Arg-OEt by trypsin (25). Conditions: $0.2 \mathrm{M}$ HEPES-buffer, $\mathrm{pH}$ 8.0, $0.2 \mathrm{M} \mathrm{NaCl}, 20 \mathrm{mM} \mathrm{CaCl}_{2}$, $25^{\circ} \mathrm{C}$; [substrate]: $2 \mathrm{mM}$, [amino component]: $20 \mathrm{mM}$; errors are less than $15 \%$.

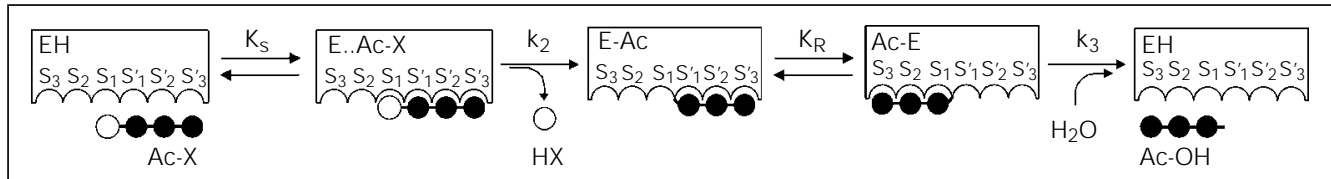

Figure 4 - Scheme of the extended kinetic model of a protease-catalyzed hydrolysis of substrate mimetics introducing the novel rearrangement equilibrium constant $K_{R}(25)$. EH, Free enzyme; Ac-X, substrate; [E..Ac-X], Michaelis-Menten complex; $\mathrm{HX}$, leaving group; $\mathrm{E}-\mathrm{Ac}$, acyl enzyme intermediate bearing the acyl residue at the $\mathrm{S}^{\prime}$ subsite; Ac-E, acyl enzyme intermediate bearing the acyl residue at the S-subsite; $\mathrm{Ac}-\mathrm{OH}$, hydrolysis product.

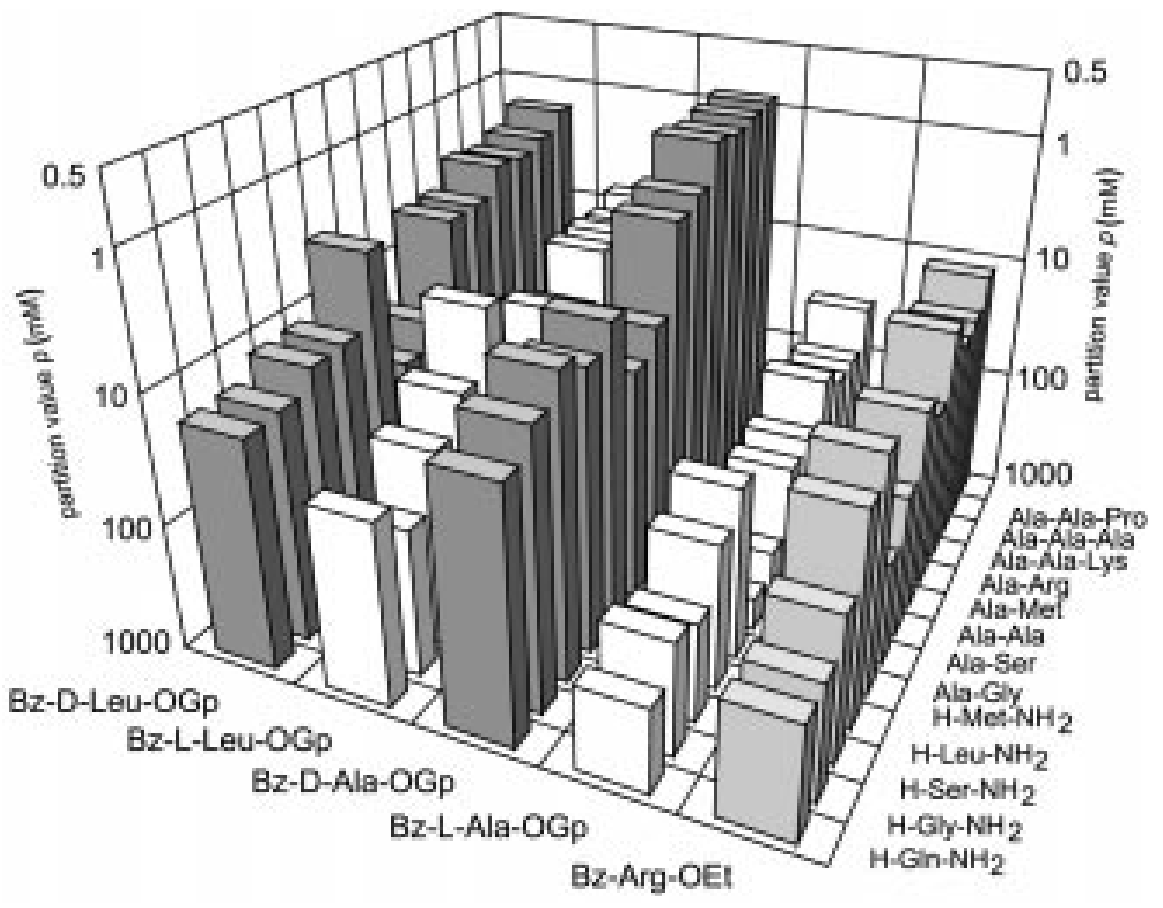


acceptors $(28,29)$ and later extended by further examples $(30,31)$. Our own studies demonstrated that, in addition to single amino acid derivatives, the 4-guanidinophenyl ester functionality also mediates coupling of nonspecific acyl moieties derived from peptides (Table 2) (27). Furthermore, Table 2 contains data obtained with other Arg-specific proteases like thrombin and clostripain, indicating that the concept of substrate mimetics is not limited to trypsin but also holds for trypsin-like enzymes. The largely varying product yields reflect the distinct synthetic utility of the individual enzymes. Generally, the highest yields were obtained with the cysteine protease clostripain, which also provided yields of over $90 \%$ for other 4 guanidinophenyl esters of acylated amino acids. An additional decisive advantage of clostripain in substrate mimetic-mediated peptide synthesis results from its low $\mathrm{P}_{1}$, specificity for the N-terminal amino acid residue of the amino component.

A further important advantage of substrate mimetic-mediated synthesis reactions results from the fact that the $\mathrm{C}$-terminal amino acid residue to be coupled does not function as a specificity determining moiety. Consequently, in contrast to enzymatic reactions using normal-type acyl donors, the peptide bond formed cannot be recognized and, therefore, cannot be cleaved again by the enzyme. As shown by the course of the $(3+5)$ segment condensation of Boc-Phe-Gly-Gly-Ala-PheAla-Ala-Gly-OH (Figure 6), the maximum product concentration achieved after a few minutes remains unchanged after $72 \mathrm{~h}$; this clearly proves the irreversibility of this $\mathrm{C}-\mathrm{N}$ bond forming method.

\section{Substrate mimetics for Glu-specific proteases}

On the basis of the insights in the binding and kinetics of substrate mimetic-mediated protease-catalyzed reactions it can be concluded that the concept of substrate mimetics might be a general principle in enzyme catalysis which is not only limited to trypsin and trypsin-like proteases. Assuming this, we expanded the substrate mimetic strategy to anionic leaving groups based on the specificity determinants of Glu-specific endopeptidase from Staphylococcus aureus (V8 protease) (32).

As shown by our docking studies on the trypsin-type model, the leaving group moiety of a substrate mimetic binds in place of the specificity-determining amino acid side chain of common substrates (25). Thus, an important condition for this function is a high affinity of the leaving group to the primary substrate specificity of the appropri-

Table 2 - Product yields of the trypsin-, thrombin-, and clostripain-catalyzed fragment condensation of Boc-Phe-Gly-Gly-OGp (2 mM) and H-Ala-PheAla-Ala-Gly-OH as a function of the concentration of the amino component (27).

Conditions: $50 \mathrm{mM}$ HEPES-buffer, pH 8.0, 100 $\mathrm{mM} \mathrm{NaCl}, 10 \mathrm{mM} \mathrm{CaCl} 2,25^{\circ} \mathrm{C}$; [trypsin]: $9.6 \mu \mathrm{M}$, [thrombin]: $22 \mu \mathrm{M}$, [clostripain]: $1.6 \mu \mathrm{M}$; n.d.: not determined.

\begin{tabular}{lccc}
\hline AFAAG (mM) & \multicolumn{3}{c}{ Product yield (\%) } \\
\cline { 2 - 4 } & Trypsin & Thrombin & Clostripain \\
\hline 2.4 & n.d. & n.d. & 83 \\
4 & 21 & 10 & 94 \\
6 & 29 & 14 & 96 \\
8 & 38 & 18 & 98
\end{tabular}

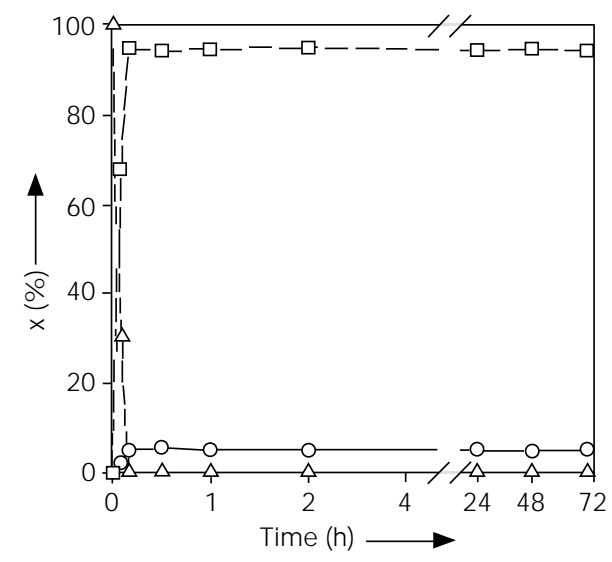

Figure 6 - Course of the clostripain-catalyzed $(3+5)$ fragment condensation of Boc-Phe-GlyGly-OGp and H-Ala-Phe-Ala-AlaGly-OH (27). Boc-Phe-Gly-GlyOGp (triangles); Boc-Phe-GlyGly-Ala-Phe-Ala-Ala-Gly-OH (squares); Boc-Phe-Gly-Gly-OH (circles). Conditions: $50 \mathrm{mM}$ HEPES-buffer, pH 8.0, 100 mM $\mathrm{NaCl}, 10 \mathrm{mM} \mathrm{CaCl} 2,25^{\circ} \mathrm{C}$; [clostripain]: $1.6 \mu \mathrm{M}$, [acyl donor]: 2 $\mathrm{mM}$, [H-Ala-Phe-Ala-Ala-Gly$\mathrm{OH}$ ]: $4 \mathrm{mM} ; \mathrm{x}=$ product yield. 
ate enzyme, i.e., to the strong Glu-preference of $\mathrm{V} 8$ protease at the $\mathrm{S}_{1}$-subsite. Unfortunately, the still unknown 3-D structure of this enzyme allows only the design of suitable mimetic moieties by empirical structure-function relationship studies based on the known natural enzyme specificity. Along this line, the carboxymethyl thioester group was selected as a potentially suitable leaving group for imitating specific Glu residues.

Table 3 - Kinetic constants for V8 protease-catalyzed hydrolysis of carboxymethyl thioester substrate mimetics compared to the normal-type substrate Z-Glu-SMe (32).

Conditions: $0.2 \mathrm{M}$ HEPES-buffer, $\mathrm{pH} 8.0,3^{\circ} \mathrm{C}$; [substrate]: $0.0125-3 \mathrm{mM}$, [enzyme]: 0.003-9.9 $\mu \mathrm{M}$; errors are less than $15 \%$.

\begin{tabular}{lc}
\hline Substrate & $\mathrm{k}_{\text {cat }} / \mathrm{K}_{\mathrm{M}}\left(\mathrm{M}^{-1} \mathrm{~S}^{-1}\right)$ \\
\hline Z-Glu-SMe & $1.12 \times 10^{4}$ \\
Z-Ala-SCm & $1.58 \times 10^{1}$ \\
Z-D-Ala-SCm & $0.97 \times 10^{1}$ \\
Z-Phe-SCm & $2.01 \times 10^{1}$ \\
Z-Ser-SCm & $0.87 \times 10^{1}$ \\
Z-Pro-SCm & $0.13 \times 10^{1}$ \\
Z-Gly-SCm & $3.34 \times 10^{1}$ \\
Z-Met-SCm & $4.60 \times 10^{1}$ \\
Z-Pro-Leu-Gly-SCm & $3.18 \times 10^{2}$ \\
Z-Phe-SCam & no hydrolysis
\end{tabular}

Table 4 - Partition values of V8 protease-catalyzed acyl transfer reactions of carboxymethyl thioester substrate mimetics with amino acid and dipeptide amides compared to Z-Glu-SMe (32).

Conditions: $0.2 \mathrm{M}$ HEPES-buffer, pH 8.0, 370 C; [acyl donor]: $2 \mathrm{mM}$, [acyl acceptor]: 20 $\mathrm{mM}$, [enzyme]: $0.3-4 \mu \mathrm{M}$; errors are less than $15 \%$.

\begin{tabular}{lcccc}
\hline \multirow{2}{*}{ Acyl donor } & \multicolumn{5}{c}{ Partition value (mM) } \\
\cline { 2 - 5 } & \multicolumn{5}{c}{ Acyl acceptor } \\
\cline { 2 - 5 } & H-Leu-NH ${ }_{2}$ & H-lle-NH & H-Leu-Ala-NH & H-Leu-Gly-NH \\
& & & & \\
\hline Z-Glu-SMe & 18.4 & 26.6 & 7.10 & 3.42 \\
Z-Ala-SCm & 17.2 & 18.7 & 12.9 & 17.6 \\
Z-D-Ala-SCm & 40.4 & 35.9 & 20.3 & 28.3 \\
Z-Phe-SCm & 3.90 & 5.40 & 4.00 & 8.11 \\
Z-Ser-SCm & 32.9 & 20.1 & 31.5 & 13.9 \\
Z-Pro-SCm & 78.1 & 82.1 & 139 & 92.2 \\
Z-Gly-SCm & 28.9 & 27.4 & 38.4 & 22.5 \\
Z-Met-SCm & 37.9 & 23.1 & 38.6 & 12.1 \\
Z-Pro-Leu-Gly-SCm & 28.8 & 31.9 & 38.1 & 21.1
\end{tabular}

The ability of the carboxymethyl thioester group to serve as an artificial recognition site for V8 protease was first been examined by steady-state hydrolysis kinetic studies. The resulting specificity constants $\left(k_{\text {cat }} / K_{\mathrm{M}}\right)$ calculated from the linear slopes of the corresponding curves are listed in Table 3 . Generally, the carboxymethyl thioester group was found to mediate a specific hydrolysis of all substrates independently of its C-terminal amino acid by V8 protease. This also holds for Pro and even for the non-coded D-conformer of Ala. Remarkably, D-Ala causes only a slight decrease in specificity compared to the L-counterpart. In contrast to this non-specificity of the enzyme for the acyl residue, the negative charge of the leaving group is essential to mimic substrates. Accordingly, the lack of this charge in the case of Z-Phe-SCam causes a complete loss of specificity. Analyzing the specificity constants for the carboxymethyl thioesters, a one to four orders of magnitude lower specificity compared to the common substrate was found. Interestingly, the elongation of the peptide chain in the case of Z-Pro-LeuGly-SCm increases the specificity by one order of magnitude compared to the shorter counterparts, resulting in a 35 -fold lower $k_{\text {cat }} / K_{\mathrm{M}}$ value than found for Z-Glu-SMe.

Further studies have evaluated the utility of carboxymethyl thioesters for V8 proteasecatalyzed peptide synthesis. For this purpose, the newly developed substrates listed in Table 3 served as acyl donors in model acyl transfer reactions using amino acid and dipeptide amides as acyl acceptors (Table 4). It was found that each carboxymethyl thioester was able to act as an acyl donor for V8 protease-catalyzed peptide synthesis independently of its acyl moiety, as predicted by the hydrolysis kinetic studies. Table 4 shows that the $p$-values observed for the substrate mimetics are comparable to that of the normal-type acyl donor Z-Glu-SMe in most cases. Moreover, when dipeptide amides were used as acyl acceptors lower $p$ - 
values were found for substrate mimetics than for Z-Glu-SMe in most cases. These findings imply a yield-increasing effect of longer acyl acceptors, especially when carboxymethyl thioesters serve as acyl donors. The results of model segment condensations reported in Figure 7 confirmed this suggestion. Consequently, for the penta- and decapeptide for both acyl acceptors lower $p$ values and, therefore, higher product yields could be obtained than found for the small dipeptide amides, whereas the decapeptide is more effective than the pentapeptide.

In addition to carboxymethyl thioesters, other types of esters mediate acceptance by V8 protease (33). Beside the one methylene group extended carboxyethyl thioester analogs, various carboxyphenyl esters and thioesters were found to be specifically hydrolyzed by V8 protease. Surprisingly, despite the lower degree of structural similarity, the aromatic part of the leaving groups led to even higher specificity constants than found for the aliphatic counterparts. This finding indicates that the degree of structural similarity between site-specific amino acid side chain and leaving group obviously does not represent the only parameter to be considered for the design of substrate mimetics.

\section{Substrate mimetics for aromatic and hydrophobic amino acid-specific proteases}

Beside proteolytic enzymes with a specificity for positively and negatively charged amino acid residues, a third important class of proteases are represented by enzymes which are specific for aromatic and hydrophobic amino acid moieties. The most wellknown representatives of this class are the serine proteases chymotrypsin and subtilisin. Both enzymes have been well investigated for classical enzymatic peptide synthesis and have been found to be suitable biocatalysts $(3,4,7)$. Therefore, the two enzymes are interesting targets for substrate mimetic- mediated reactions.

With respect to natural specificity, chymotrypsin and subtilisin primarily prefer large hydrophobic and aromatic amino acid residues. Furthermore, the $\mathrm{S}_{1}$-binding pocket of subtilisin contains a carboxylic acid moiety (Glu156) which causes additional activity towards Arg and Lys (34). Thus, aromatic leaving groups with additional positively charged substitutions, e.g., 4-guanidinophenyl esters, should fit well the natural specificity of the enzymes.

In addition to this empirical design of specific mimetic moieties, the known protein structures of the two proteases also allow the use of rational approaches. Especially, the already described computer-assisted protein-ligand docking approach seems to be helpful for the design and optimization of leaving groups with a high binding specificity. Moreover, on the basis of knowledge about substrate mimetic recognition and the mechanism of catalysis, this approach may also allow an estimation of whether the calculated binding leads to hydrolysis. Thus, we utilized the docking approach to predict the function of the 4-guanidinophenyl ester functionality to act as an artificial recognition site for chymotrypsin (Günther R, Thust S, Hofmann H-J and Bordusa F, unpublished

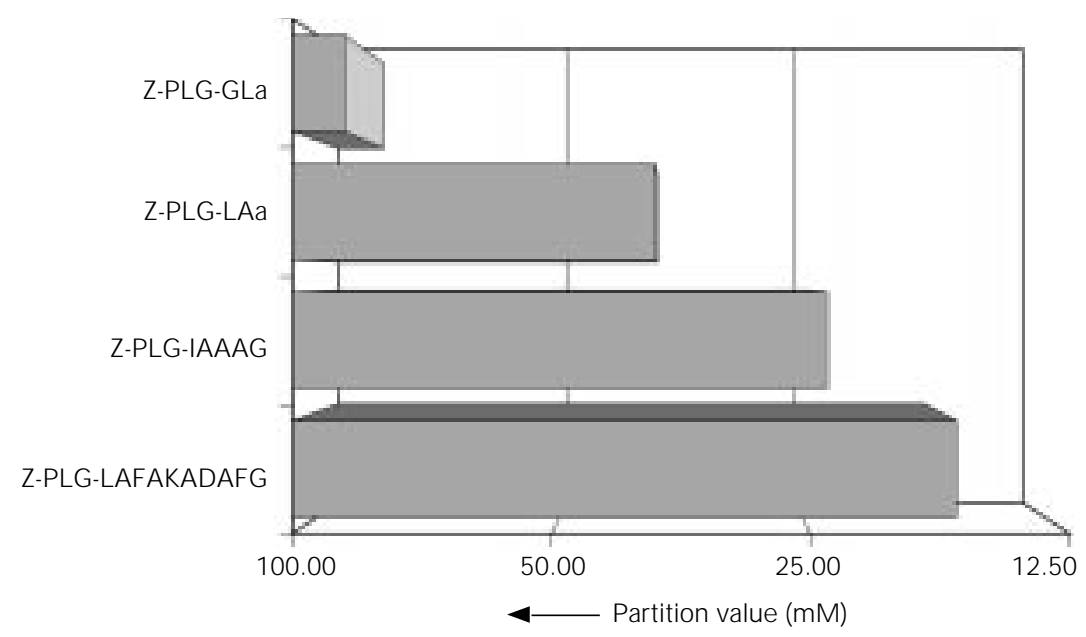

Figure 7 - Partition values of V8 protease-catalyzed peptide coupling using Z-Pro-Leu-GlySCm as acyl donor (32). Conditions: $0.2 \mathrm{M} \mathrm{HEPES}-$ buffer, $\mathrm{pH} 8.0$, 370 $\mathrm{C}$; [acyl donor]: $2 \mathrm{mM}$, [LAFAKADAFG]: $10 \mathrm{mM}$, [dipeptide amides, IAAAG]: $20 \mathrm{mM}$, [enzyme]: $4.9 \mu \mathrm{M}$. 
results). For this purpose, Boc-L-Ala-OGp was selected as a model ligand and docked towards the enzyme. Figure 8 shows the arrangement of the ligand at the active site of chymotrypsin in the lowest energy complex (A) in comparison to that found for trypsin (B) (25). Corresponding to the natural specificity of chymotrypsin, hydrophobic contacts between the phenyl moiety of the ester group and the amino acid residues Cys191 and Val213 of the enzyme predominate. Moreover, the guanidino functionality fa-

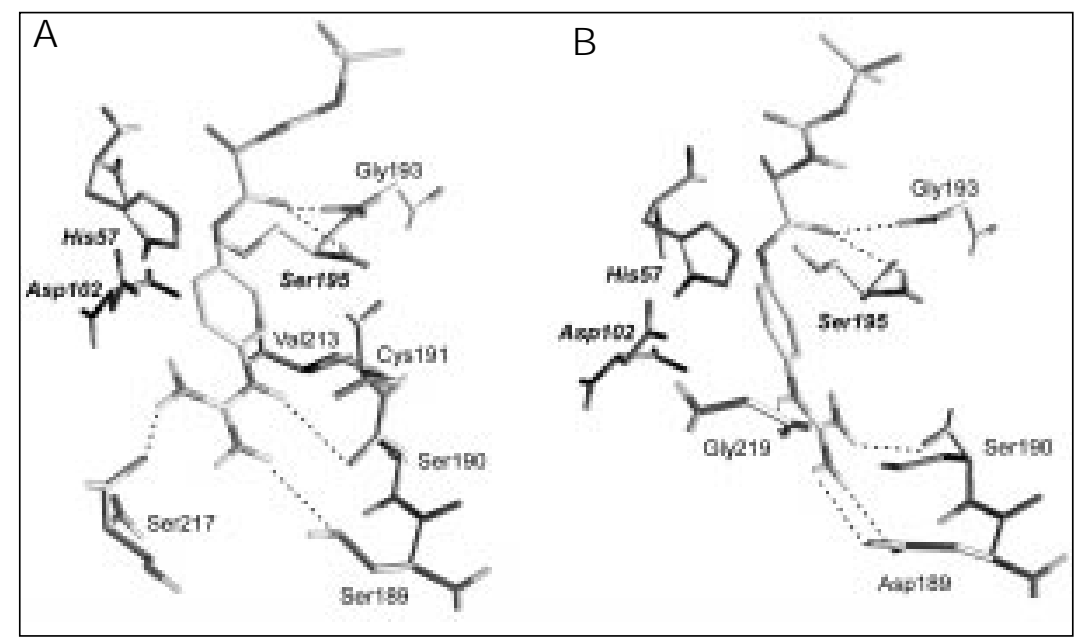

Figure 8 - Arrangements of Boc-L-Ala-OGp at the active sites of chymotrypsin (A) and trypsin (B) derived from the lowest-energy complexes (Günther R, Thust S, Hofmann H-J and Bordusa $F$, unpublished results). Shown are the amino acid residues of the enzymes which either form hydrogen bonds (Asp189/Ser189, Ser190, Ser217/Gly219) or have catalytical functions (His57, Asp102, and Ser195).

Table 5 - Steady-state kinetic parameters for the chymotrypsin-catalyzed hydrolysis of 4-guanidinophenyl esters (Günther R, Thust S, Hofmann H-J and Bordusa F, unpublished results).

Conditions: $25 \mathrm{mM}$ MOPS-buffer, $\mathrm{pH} 7.6,0.1 \mathrm{M} \mathrm{NaCl}, 5 \mathrm{mM} \mathrm{CaCl} 2,25^{\circ} \mathrm{C}, 20 \% \mathrm{MeOH}$. ${ }^{a}$ Calculated as linear slope of the initial Michaelis-Menten curve in relation to the active enzyme concentration; all errors are less than $15 \%$.

\begin{tabular}{lccc}
\hline Substrate & $\mathrm{K}_{\mathrm{M}}(\mathrm{mM})$ & $\mathrm{k}_{\text {cat }}\left(\mathrm{s}^{-1}\right)$ & $\mathrm{k}_{\text {cat }} / \mathrm{K}_{\mathrm{M}}\left(\mathrm{M}^{-1} \mathrm{~s}^{-1}\right)$ \\
\hline Boc-Gly-OGp & 2.81 & 1.18 & $4.20 \times 10^{2}$ \\
Boc-L-Ala-OGp & 2.88 & 10.4 & $3.61 \times 10^{3}$ \\
Boc-D-Ala-OGp & 4.94 & 0.56 & $1.13 \times 10^{2}$ \\
Boc-L-Glu-OGp & - & - & $1.48 \times 10^{2}$ \\
Boc-L-Pro-OGp & - & - & $0.45 \times 10^{1}$ \\
Boc-D-Phe-OGp & 2.58 & 5.45 & $2.11 \times 10^{3}$ \\
Boc-D-Leu-OGp & 1.49 & 3.04 & $2.04 \times 10^{3}$ \\
Bz-OGp & 0.44 & 0.13 & $2.96 \times 10^{2}$ \\
\end{tabular}

vors this binding mode by formation of additional hydrogen bonds with several serine residues which are located at the bottom of the $\mathrm{S}_{1}$-binding pocket. Mediated by the specific binding of the leaving group, the conditions for the catalytic mechanism and the binding behavior of substrate mimetics, namely the orientation of the carbonyl oxygen to Gly193 (oxanion hole), the distance between the carbonyl carbon of the scissile ester bond and the active Ser195, and the reversed binding of the acyl moiety are fulfilled. Since this arrangement leads to specific cleavage of the substrate in the case of trypsin, chymotrypsin should also be capable of hydrolyzing acyl-4-guanidinophenyl esters. This prediction was confirmed by steady-state hydrolysis kinetic studies using several Boc-Xaa-OGp esters and the nonamino acid-derived analog benzoic acid ester (Bz-OGp) (Table 5). These findings impressively show that the computer-assisted protein-ligand docking approach can serve as a useful tool to predict a priori acceptance of a given substrate mimetic by the enzyme. Further studies on the applicability of this rational approach to the optimization or design of novel types of substrate mimetics leading to more specific binding and higher acylation rates are currently underway.

Since substrate mimetics are obviously meaningful in protease-mediated peptide synthesis, the predictions of the computational approach were also examined by acyl transfer reactions (Figure 9). The results of these studies show that the 4-guanidinophenyl ester functional group enables chymotrypsin to catalyze the peptide bond formation between nonspecific coded and non-coded acyl residues and numerous amino acid and peptide derivatives. By analyzing the efficiency of catalysis for substrate mimetics, yields similar to those found for the normal-type acyl donor Bz-L-Phe-OMe could be obtained. This also holds for reactions with the nonamino acid-derived Bz-OGp, indicating that 4-guanidinophenyl esters of simple car- 
boxylic acids can also act as efficient acyl donor components for chymotrypsin-catalyzed coupling. Consequently, chymotrypsin can be used as an efficient biocatalyst for coupling a wide spectrum of acyl components different from those of its natural specificity in form of their 4-guanidinophenyl esters. Furthermore, due to the acceptance of 4-guanidinophenyl esters by trypsin and proteases with trypsin-like specificity, this type of substrate mimetics becomes of general utility for several proteases.

Alternatively, the computer-assisted docking approach can also be used for the design of enzyme-selective mimetic moieties. Simple phenyl ester analogs, for example, are practically no substrates for trypsin or trypsin-like enzymes but are specifically hydrolyzed by chymotrypsin (Bigl K and Bordusa $\mathrm{F}$, unpublished data).

\section{Combination of solid-phase peptide synthesis and substrate mimetic- mediated segment condensation}

An important field of application of pro- teases is the synthesis of longer peptides by the condensation of peptide fragments. An essential condition for this function is the chemical synthesis of peptide esters which can further be used as acyl donors in enzymatic reactions. Consequently, the utilization of the substrate mimetic strategy for the protease-mediated condensation of peptide fragments indisputably needs a combination with chemical methods, primarily with solidphase peptide synthesis. As known from the literature, the synthesis of peptide esters can be achieved by utilizing the oxime resin strategy (35-37). While earlier work established the general applicability of this methodology, we investigated its usefulness for the synthesis of peptide esters in the form of various substrate mimetics (cf. Figure 10A) (38). The synthesis protocol involves covalent attachment of the first $N^{\alpha}$-Boc-protected amino acid to the oxime resin, acetylation of free hydroxylic groups by acetic anhydride, deprotection of the $N^{\alpha}$-amino group of the attached amino acid, followed by in situ coupling of the next $N^{\alpha}$-Boc-protected amino acid. The peptide esters can be generated by

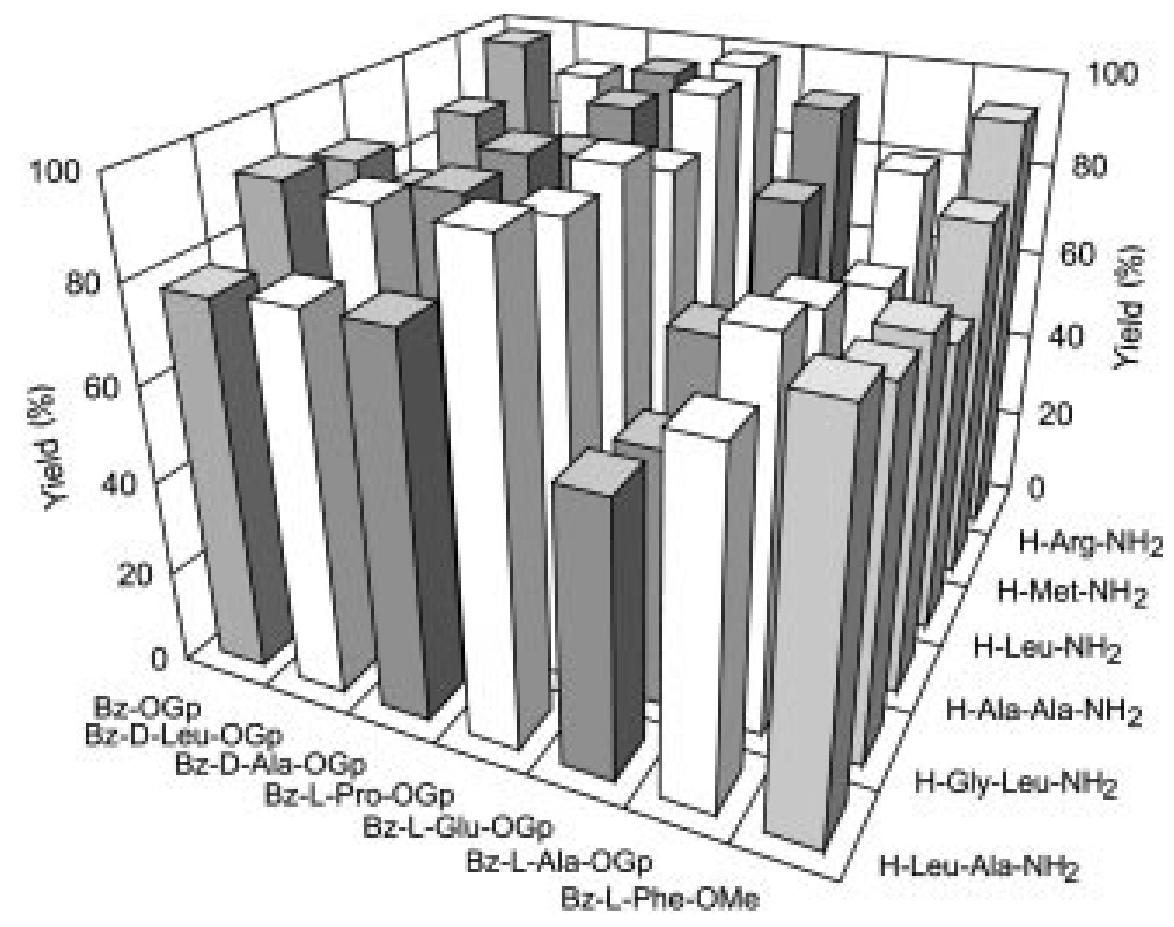

Figure 9 - Yields of chymotrypsin-catalyzed peptide synthesis using 4-guanidinophenyl esters bearing nonspecific coded and non-coded acyl moieties (Günther R, Thust S, Hofmann $\mathrm{H}-\mathrm{J}$ and Bordusa $F$, unpublished results). Conditions: 0.2 M HEPESbuffer, $\mathrm{pH}$ 8.0, $0.2 \mathrm{M} \mathrm{NaCl}, 20$ $\mathrm{mM} \mathrm{CaCl} 2,25^{\circ} \mathrm{C}, 10 \% \mathrm{MeOH}$; [acyl donor]: $2 \mathrm{mM}$, [acyl acceptor]: $20 \mathrm{mM}$, [enzyme]: 0.1-37 $\mu \mathrm{M}$; all errors are less than $5 \%$. 
aminolysis of the oxime ester linkage between peptide and resin using appropriate $N^{\alpha}$-deprotected amino acid esters. By utilizing this strategy several peptide esters could be synthesized in the form of different substrate mimetics (Figure 11). After final deprotection of the ester leaving group and side chains of trifunctional amino acids, the peptide esters 2, 5, and 9 have served as acyl

Figure 10 - General course of peptide ester synthesis via oxime resin strategy (A) and substrate mimeticmediated peptide fragment condensation by protease catalysis (B).

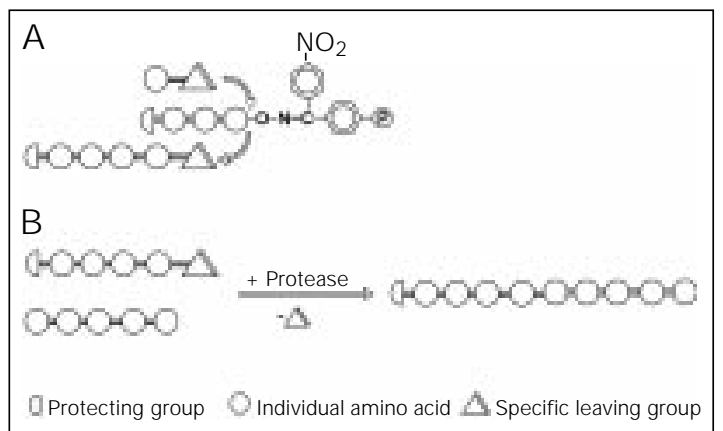

Figure 11 - Combination of solid-phase peptide synthesis via oxime resin strategy with trypsin- (A), V8 protease- $(B)$, and chymotrypsin-catalyzed fragment condensation (C) (38).

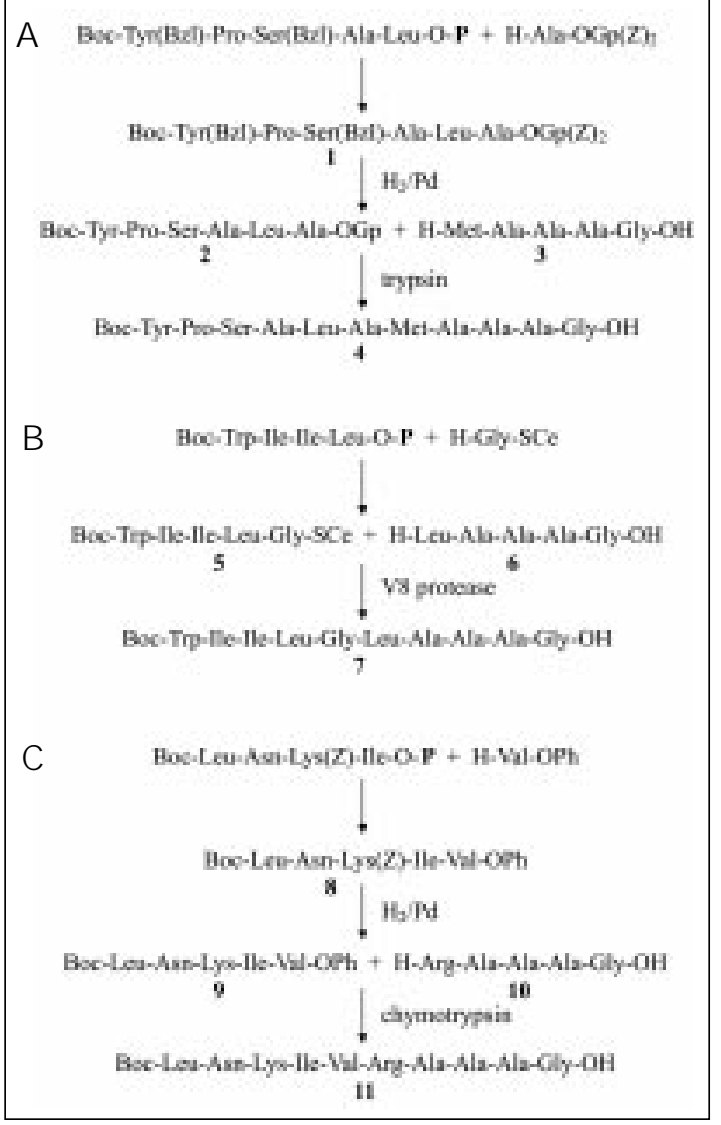

donors for trypsin-, V8 protease-, and chymotrypsin-catalyzed fragment condensation, as schematically illustrated in Figure 10B. The reactions were performed on a preparative scale using 1:2 ratios of acyl donors to acyl acceptors (V8 protease and chymotryp$\sin$ ) or 1:2.5 (trypsin). The appropriate peptide products 4,7 , and 11 were obtained in $60-70 \%$ yields, demonstrating the high synthetic utility of substrate mimetics for the protease-mediated condensation of peptide fragments.

\section{Substrate mimetic-mediated synthesis of carboxylic acid amides}

In contrast to the mostly high primary specificity of proteases, the specificity towards the acyl acceptor (S'-subsite specificity) is frequently more relaxed, generally allowing the coupling of a wider spectrum of acyl acceptors (7). Nevertheless, the product yields usually drop with increasing degree of modification of both the amino acid side chain and the backbone structure, particularly at the $\mathrm{P}_{1}$ '-position. Therefore, only the coupling of acyl acceptors closely related to preferred amino acid residues is of practical relevance, as shown for selected synthesis (39-41). The enzymatic synthesis of peptide isosteres or analogs, however, requires strategies which allow the coupling of a broader variety of modified amino acid derivatives and also non-amino acid-derived building blocks. In this context, the use of esterases and particularly of lipases seems to be of higher synthetic utility (42-44). Due to the broader substrate specificities of these enzymes, an extended structural diversity of amines and esters undergo the esterase- and lipase-catalyzed aminolysis reaction in preferably anhydrous solvents. However, the organic solvent itself considerably affects the activity of these enzymes, as well as the yield, regio- and stereospecificity of such reactions (45). Thus, a very careful and often time-consuming optimization of reaction con- 
ditions is required, which prevents the use of esterases and lipases from being easily and universally applicable. Recently, we presented an alternative protease-mediated approach to the coupling of non-coded and non-amino acid-derived amines with esters (46). The key feature of this method is the combination of the substrate mimetic strategy with the use of clostripain which possesses a broad tolerance toward amines (47). The general ability of the 4-guanidinophenyl ester functionality to mediate acceptance of non-coded and non-amino acid-derived acyl components by clostripain was demonstrated in reactions of the acyl donors Pbu-OGp and Bz-B-Ala-OGp with several amino acid and peptide units used as amino components (Table 6). Typical time courses of such reactions are illustrated in Figure 12. Generally, the data show that productive binding and acylation of the enzyme, finally resulting in proteolytically stable amide products, are found with the non-coded but naturally occurring B-Ala-derivative as well as the nonamino acid-derived 4-phenylbutyric acid ester. Analysis of the efficiency of catalysis showed that product yields within a range of 83 to $98 \%$ were reached in all cases, usually higher than $90 \%$. Remarkably, reducing the excess of acyl acceptor, studied for reactions with the pentapeptide, does not decrease the efficiency of coupling reactions with both esters. This atypical behavior indicates that reaching satisfactory yields does not require a large excess of either reactant. This shows the synthetic utility of clostripain also for the coupling of more valuable carboxyl and amino components.

Apart from the highly restricted primary specificity, clostripain practically accepts all coded amino acids and also some D-configured counterparts as amino components $(48,49)$. Moreover, using a wide range of non-coded acyl acceptors we surprisingly found that clostripain even tolerates amino components considerably different from coded amino acids, such as simple aliphatic, aromatic or substituted amines including unnatural amino acids, amino alcohols, and diamines (47). This unique specificity distinguishes clostripain from most other known proteases, although little is known about the structural bases of this remarkable behavior. From the synthetic point of view, this broad specificity combined with the substrate mimetic strategy might open an entirely new field of application of this protease to the synthesis of organic amides completely outside of peptide synthesis. To investigate

Table 6 - Clostripain-catalyzed coupling of Bz-ß-Ala-OGp and Pbu-OGp with selected amino acid amides and peptides (46).

Conditions: $0.2 \mathrm{M}$ HEPES-buffer, $\mathrm{pH}$ 8.0, $0.1 \mathrm{M} \mathrm{NaCl}, 10 \mathrm{mM} \mathrm{CaCl} 2,5 \% \mathrm{DMF}, 25^{\circ} \mathrm{C}$; [acyl donor]: $2 \mathrm{mM}$, [acyl acceptor]: $25 \mathrm{mM}$. a[H-Lys-NH ]: $15 \mathrm{mM}$. b[H-Glu-NH ]: 50 mM. C[H-AFAAG-OH]: 4 mM.

\begin{tabular}{|c|c|c|c|}
\hline Acyl donor & Acyl acceptor & Amide product & Yield (\%) \\
\hline Pbu-OGp & H-Leu-NH 2 & Pbu-Leu-NH ${ }_{2}$ & 98 \\
\hline Pbu-OGp & $\mathrm{H}$-Lys- $\mathrm{NH}_{2}{ }^{\mathrm{a}}$ & Pbu-Lys-NH 2 & 96 \\
\hline Pbu-OGp & $\mathrm{H}-$ Glu-NH${ }_{2}{ }^{\mathrm{b}}$ & Pbu-Glu-NH 2 & 87 \\
\hline Pbu-OGp & H-Pro-NH ${ }_{2}$ & Pbu-Pro- $\mathrm{NH}_{2}$ & 83 \\
\hline Pbu-OGp & H-Ala-Pro-OH & Pbu-Ala-Pro-OH & 93 \\
\hline Pbu-OGp & $\mathrm{H}-\mathrm{AAP}-\mathrm{OH}$ & Pbu-AAP-OH & 86 \\
\hline Pbu-OGp & H-AFAAG-OHC & Pbu-AFAAG-OH & 92 \\
\hline Bz-ß-Ala-OGp & H-Leu-NH 2 & Bz-ß-Ala-Leu-NH 2 & 98 \\
\hline Bz-ß-Ala-OGp & $\mathrm{H}$-Lys- $\mathrm{NH}_{2}{ }^{\mathrm{a}}$ & Bz-ß-Ala-Lys-NH 2 & 93 \\
\hline Bz-ß-Ala-OGp & H-Glu-NH ${ }_{2}^{b}$ & Bz-ß-Ala-Glu-NH & 89 \\
\hline Bz-ß-Ala-OGp & H-Pro-NH ${ }_{2}$ & Bz-ß-Ala-Pro-NH 2 & 90 \\
\hline Bz-ß-Ala-OGp & H-Ala-Pro-OH & Bz-ß-Ala-Ala-Pro-OH & 91 \\
\hline Bz-ß-Ala-OGp & $\mathrm{H}-\mathrm{AAP}-\mathrm{OH}$ & Bz-ß-Ala-AAP-OH & 85 \\
\hline Bz-ß-Ala-OGp & $\mathrm{H}$-AFAAG-OHC & Bz-ß-Ala-AFAAG-OH & 93 \\
\hline
\end{tabular}

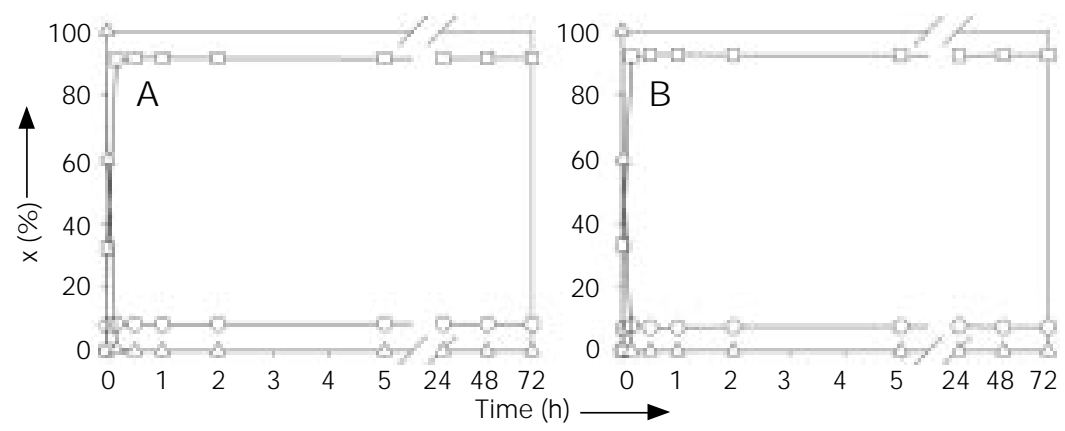

Figure 12 - Course of the clostripain-catalyzed coupling of Bz-B-Ala-OGp and Pbu-OGp with H-Ala-Phe-Ala-Ala-Gly-OH (44). A, Bz-ß-Ala-OGp; B, Pbu-OGp. Triangles, Bz-ß-Ala-OGp/PbuOGp; squares, Bz-B-Ala-Ala-Phe-Ala-Ala-Gly-OH/Pbu-Ala-Phe-Ala-Ala-Gly-OH; circles, Bz-ßsAla-OH/Pbu-OH. Conditions: 0.2 M HEPES-buffer, pH 8.0, 0.1 M NaCl, $0.01 \mathrm{M} \mathrm{CaCl}_{2}, 5 \%$ DMF, $25^{\circ} \mathrm{C}$; [acyl donor]: $2 \mathrm{mM}$, [acyl acceptor]: $4 \mathrm{mM}$; $\mathrm{x}=$ product yield. 
whether this approach can be used in such a manner, enzymatic reactions were performed between 4-guanidinophenyl esters of benzoic acid (Bz-OGp) and 4-phenylbutyric acid (Pbu-OGp), and a number of non-amino acidderived amino components (46). Generally, the results listed in Table 7 show that clostri- pain is capable of catalyzing the coupling of both non-amino acid-derived carboxyl and amino components as indicated by individual experiments. With respect to the efficiency of catalysis, most enzymatic reactions led to product yields higher than $70 \%$. Accordingly, only small amounts of hydrolysis prod-

Table 7 - Clostripain-catalyzed coupling of non-amino acid-derived carboxyl and amino components (46).

Conditions: 0.2 M HEPES-buffer, pH 8.0, $0.1 \mathrm{M} \mathrm{NaCl}, 10 \mathrm{mM} \mathrm{CaCl}_{2}, 5 \% \mathrm{DMF}, 25^{\circ} \mathrm{C}$; [acyl donor]: $2 \mathrm{mM}$, [acyl acceptor]: $12 \mathrm{mM}$. n. s.: No synthesis.

\begin{tabular}{|c|c|c|c|}
\hline Acyl donor & Acyl acceptor & Amide product & Yield (\%) \\
\hline$\overline{\mathrm{Pbu}-\mathrm{OGp}}$ & $\mathrm{H}_{2} \mathrm{~N}$ & $\mathrm{PbuNH}^{\prime}$ & 81 \\
\hline Pbu-OGp & $\mathrm{H}_{2} \mathrm{~N}$ & $\mathrm{Pbu}-\mathrm{NH}$ & 80 \\
\hline Pbu-OGp & $\mathrm{H}_{2} \mathrm{~N}$ & Pbu-NI & 53 \\
\hline Pbu-OGp & $\mathrm{H}_{2} \mathrm{~N}^{-}$ & PbunH & 65 \\
\hline $\mathrm{Pbu}-\mathrm{OGp}$ & $\mathrm{H}_{2} \mathrm{~N}^{-}$ & PbuNH & 78 \\
\hline Pbu-OGp & $\mathrm{H}_{2} \mathrm{~N}$ & $\mathrm{Pbu}-\mathrm{N}$ & 70 \\
\hline Pbu-OGp & $\mathrm{H}_{2} \mathrm{~N}^{-}$ & Pbu-NF & 92 \\
\hline Pbu-OGp & $\mathrm{H}_{2} \mathrm{~N}^{-}$ & PburNI & 95 \\
\hline Pbu-OGp & Ho' & Pbu-O & n. $\mathrm{s}$. \\
\hline Bz-OGp & $\mathrm{H}_{2} \mathrm{~N}^{-}$ & $\mathrm{Bz}-\mathrm{NH}^{-}$ & 82 \\
\hline $\mathrm{Bz}-\mathrm{OGp}$ & $\mathrm{H}_{2} \mathrm{~N}$ & $\mathrm{Bz}-\mathrm{NH}^{-}$ & 76 \\
\hline $\mathrm{Bz}$-OGp & $\mathrm{H}_{2} \mathrm{~N}$ & $\mathrm{Bz}-\mathrm{NH}^{\prime}$ & 56 \\
\hline $\mathrm{Bz}-\mathrm{OGp}$ & $\mathrm{H}_{2} \mathrm{~N}^{-}$ & $\mathrm{Bz}-\mathrm{NH}^{-}$ & 57 \\
\hline $\mathrm{Bz}-\mathrm{OG} \mathrm{p}$ & $\mathrm{H}_{2} \mathrm{~N}^{\prime}$ & $\mathrm{Bz}-\mathrm{NH}^{-}$ & 84 \\
\hline$B z-O G p$ & $\mathrm{H}_{2} \mathrm{~N}^{-}$ & $\mathrm{Bz}-\mathrm{NH}^{-}$ & 70 \\
\hline Bz-OGp & $\mathrm{H}_{2} \mathrm{~N}^{-}$ & $\mathrm{Bz}-\mathrm{NH}$ & 82 \\
\hline$B z-O G p$ & $\mathrm{H}_{2} \mathrm{~N}$ & $\mathrm{Bz}-\mathrm{NH}$ & 94 \\
\hline Bz-OGp & HO & $\mathrm{B}_{2}=\mathrm{O}$ & n. s. \\
\hline
\end{tabular}


ucts $(\mathrm{Bz}-\mathrm{OH}$ and $\mathrm{Pbu}-\mathrm{OH})$ were formed. These results become even more impressive if we consider that only traces ( 0.22 to $3.7 \%$ depending on the respective $\mathrm{p} K$ value) of the amino components are deprotonated under the $\mathrm{pH}$ conditions used and, therefore, can serve as deacylating components. Contrary to most chemical methods, an increase in $\mathrm{pH}$ to completely deprotonate the amino group of the nucleophilic component is restricted by the limited intrinsic stability of enzyme and acyl donor ester. Figure 13 shows the dependence of the product yield on the concentration of pentylamine which possesses the highest $\mathrm{p} K$ value (10.65) of all amines used. The plots for both acyl donor esters illustrate that even an initial nucleophile concentration of $4 \mathrm{mM}$, which corresponds to a concentration of deprotonated pentylamine of only $0.009 \mathrm{mM}$, already leads to product yields of approximately $50 \%$. The results obtained at higher pentylamine concentrations reveal that an increase of nucleophile excess results in nearly complete conversion of the acyl donor esters to the appropriate amides. Accordingly, from the synthetic point of view, this enzymatic approach achieves highly efficient amide bond formation combined with extraordinarily mild reaction conditions. Moreover, neither additional hydroxyl groups nor amine groups within the amino component seem to limit this high synthetic utility. Apart from this high efficiency, clostripain catalyzes the acylation of substituted amines with a remarkably high degree of regiospecificity. As indicated by the lack of acceptance of 1-pentanol, no competitive formation of O-acylated products could be detected for the amino alcohols. In the same way, the acylation of ethanol, 1propanol, and 1-octanol failed (data not shown), indicating that clostripain generally does not tolerate alcohols as deacylating components. Interestingly, the asymmetric 1,3diaminopentane was acylated by the enzyme exclusively on the amino group at position 1 ,

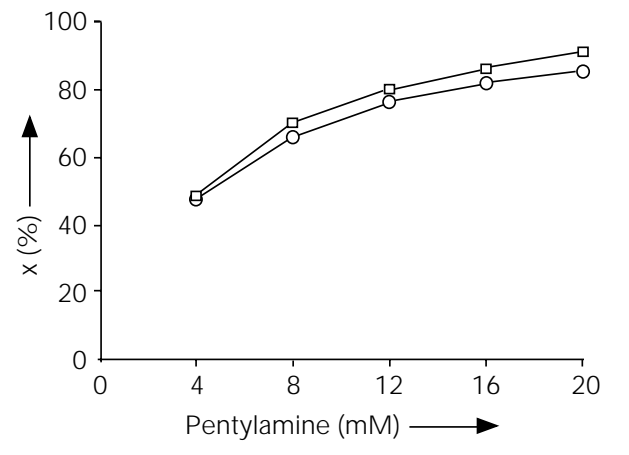

Figure 13 - Influence of pentylamine concentration on the product yield $x$ of the clostripain-catalyzed coupling of Y-OGp with pentylamine (46). Circles, $Y=$ $\mathrm{Bz}$; squares, $\mathrm{Y}=\mathrm{Pbu}$. Conditions: $0.2 \mathrm{M}$ HEPES-buffer, $\mathrm{pH}$ 8.0, $0.1 \mathrm{M} \mathrm{NaCl}, 10 \mathrm{mM} \mathrm{CaCl}_{2}$, $5 \%$ DMF, $25^{\circ} \mathrm{C}$; [acyl donor]: 2 $\mathrm{mM}$; reaction time: about 15 $\min$

with no acylation of the amino group at position 3. This finding indicates that clostripain accepts amines containing a neighboring branch less well than comparable non-branched derivatives. On the basis of this distinct specificity, clostripain should be a useful tool for selective acylation forming isomerically pure products, without large experimental efforts to protect additional functionalities.

In summary, the data described here convincingly show that the substrate mimetic strategy combined with the use of proteases possessing a broad specificity towards the amino component represents a powerful approach to the coupling of both non-amino acid-derived carboxyl and amino components. Since the classical protease-mediated synthesis used so far is usually restricted to the coupling of amino acid and peptide moieties, this approach could open up a new field of synthetic applications of these enzymes completely outside peptide synthesis. This combines efficient and selective organic amide bond formations with the possibility of using extraordinarily mild reaction conditions.

\section{Acknowledgments}

I am grateful to Prof. Dr. H.-D. Jakubke for advice and discussions. Furthermore, I thank Prof. Dr. H.-J. Hofmann, Prof. Dr. G. Fischer and my co-workers, who are listed in the references, for their contributions. 


\section{References}

1. Gassen H-G (1982). Das bakterielle Ribosom: ein programmierbares Enzym. Angewandte Chemie, 94: 15-26.

2. Kleinkauf $H$, van Liempt $H$, Palissa $H \&$ van Döhren H (1992). Biosynthese von Peptiden: Ein nichtribosomales System. Naturwissenschaften, 79: 153-162.

3. Schellenberger V \& J akubke H-D (1991). Protease-catalyzed kinetically controlled peptide synthesis. Angewandte Chemie International Edition in English, 30: 14371449.

4. Wong C-H (1989). Enzymatic catalysis in organic synthesis. Science, 244: 11451152.

5. Hoppe D (1998). In: Rehm HJ \& Reed G (Editors), Biotechnology. 2nd edn. Vol. 8a. Wiley-VCH, Weinheim, 244-262.

6. J akubke H-D, Kuhl P \& Könnecke A (1985). Basic principles of protease-catalyzed peptide bond formation. Angewandte Chemie International Edition in English, 24: 85-93.

7. J akubke H-D (1987). In: Udenfriend S \& Meienhofer J (Editors), The Peptides: Analysis, Biology. Vol. 9. Academic Press, New York, 103-165.

8. Schechter I \& Berger A (1967). On the size of the active site in proteinases. I. Papain. Biochemical and Biophysical Research Communications, 27: 157-162.

9. Cerovsky V, Wünsch W \& Brass J (1997). Enzymatic semisynthesis of dicarba analogs of calcitonin. European J ournal of Biochemistry, 247: 231-237.

10. J ackson DY, Burnier J, Quan C, Stanley M, Tom J \& Wells J A (1994). A designed peptide ligase for total synthesis of ribonuclease $A$ with unnatural catalytic residues. Science, 266: 243-247.

11. J akubke H-D (1994). Protease-catalyzed peptide synthesis: basic principles, new synthesis strategies and medium engineering. J ournal of Chinese Chemical Society, 41: 355-370.

12. Zhong Z, Liu J L-C, Dinterman LM, Finkelman MAJ, Mueller WT, Rollence ML, Whitlow M \& Wong C-H (1991). Engineering subtilisin for reaction in dimethylformamide. J ournal of the American Chemical Society, 113: 683-684.

13. J anssen AEM \& Halling PJ (1994). Specificities of enzymes "corrected for solvation" depend on the choice of the standard state. J oumal of the American Chemical Society, 116: 9827-9830.

14. Affleck R, Xu Z-F, Suzawa V, Focht K, Clark DS \& Dordick J S (1992). Enzymatic catalysis and dynamics in low-water environment. Proceedings of the National Academy of Sciences, USA, 89: 1100-1104.

15. Dominguez A, Cabezas N, SanchezMontero J M \& Sinisterra JV (1995). Chemoselectivity of chemically modified alpha-chymotrypsin. Tetrahedron, 51: 1827-1844.

16. Arnold FH \& Chen K (1994). Tuning the activity of an enzyme for unusual environments: Sequential random mutagenesis of subtilisin E for catalysis in dimethylformamide. Proceedings of the National Academy of Sciences, USA, 90: 56185622.

17. West J B, Scholten J, Stolowich NJ , Hogg J L, Scott Al \& Wong C-H (1988). Modification of proteases to esterases for peptide synthesis: Methylchymotrypsin. J ournal of the American Chemical Society, 110: 3709-3710.

18. Sears $P$, Schuster $M$, Wang $P$, Witte $K \&$ Wong C-H (1994). Engineering subtilisin for peptide coupling: Studies on the effects of counterions and site-specific modifications on the stability and specificity of the enzyme. J ournal of the American Chemical Society, 116: 6521-6530.

19. Fersht A (1984). Enzyme Structure \& Mechanism. 2nd edn. W.H. Freeman \& Co., New York

20. Imperiali $B \&$ Abeles RH (1987). Extended binding inhibitors of chymotrypsin that interact with leaving group subsites S'1S'3. Biochemistry, 26: 4474-4477.

21. Butenas S, Kalafatis M \& Mann KG (1997). Analysis of tissue plasminogen activator specificity using peptidyl fluorogenic substrate Titel. Biochemistry, 36: 2123-2131.

22. Breddam K \& M eldal M (1992). Substrate preferences of glutamic acid-specific endopeptidases assessed by synthetic peptide substrates based on intramolecular fluorescence quenching. European J ournal of Biochemistry, 206: 103-107.

23. Wagner G\& Horn H (1973). Synthese antiproteolytisch wirksamer Arylcarbon-, Aralkylcarbon- und Arylsulfonsäureester von Amidinophenolen. Pharmazie, 28: 428-431.

24. Tanizawa K, Kasaba Y \& Kanaoka Y (1977). "Inverse substrates" for trypsin. Efficient enzymatic hydrolysis of certain esters with a cationic center in the leaving group. J ournal of the American Chemical Society, 99: 4484-4488.

25. Thormann M, Thust S, Hofmann H-J \& Bordusa F (1999). Protease-catalyzed hy- drolysis of substrate mimetics: A new approach reveals a new mechanism. Biochemistry, 38: 6056-6062.

26. Huber R, Bode W, Deisenhofer J \& Schwager P (1983). The geometry of the reactive site and of the peptide groups in trypsin, trypsinogen and its complexes with inhibitors. Acta Crystallographica, Section B, 39: 480-490.

27. Bordusa F, Ullmann D, Elsner C \& J akubke H-D (1997). Substrate mimetic-mediated peptide synthesis: An irreversible ligation strategy that is independent of substrate specificity. Angewandte Chemie International Edition in English, 36: 2473-2475.

28. Schellenberger V, J akubke H-D, Zapevalova NP \& Mitin YV (1991). Proteasecatalyzed peptide synthesis using inverse substrates: The influence of reaction conditions on the trypsin acyl transfer efficiency. Biotechnology and Bioengineering, 38: 104-108.

29. Mitin YV, Schellenberger $V$, Schellenberger U, Jakubke H-D \& Zapevalova NP (1991). Protease-catalyzed peptide synthesis using inverse substrates. In: Giralt E \& Andreu D (Editors), Peptides 1990. ESCOM, Leiden, 287-288.

30. Sekizaki H, Itoh K, Toyota E \& Tanizawa K (1996). Synthesis and tryptic hydrolysis of p-guanidinophenyl esters derived from amino acids and peptides. Chemical and Pharmaceutical Bulletin, 44: 1577-1579.

31. Sekizaki H, Itoh K, Toyota E \& Tanizawa K (1996). Trypsin-catalyzed peptide synthesis with various $p$-guanidinophenyl esters as acyl donors. Chemical and Pharmaceutical Bulletin, 44: 1585-1587.

32. Wehofsky N \& Bordusa F (1998). Programming of enzyme specificity by substrate mimetics: investigations on the Gluspecific $\mathrm{V} 8$ protease reveals a novel general principle of biocatalysis. FEBS Letters, 443: 220-224.

33. Wehofsky N, Wissmann J-D, Alisch M \& Bordusa $F$ (2000). Engineering of substrate mimetics as novel-type substrates for glutamic acid-specific endopeptidases. Biochimica et Biophysica Acta (in press).

34. Morree WJ , Sears P, Kawashiro K, Witte K \& Wong C-H (1997). Exploitation of subtilisin BPN' as catalyst for the synthesis of peptides containing noncoded amino acids, peptide mimetics, and peptide conjugates. J ournal of the American Chemical Society, 119: 3942-3947.

35. Degrado WF \& Kaiser ET (1980). Polymerbound oxime esters as supports for solid- 
phase peptide synthesis. Preparation of protected peptide fragments. J ournal of Organic Chemistry, 45: 1295-1300.

36. Degrado WF \& Kaiser ET (1982). Solidphase synthesis of protected peptides on a polymer-bound oxime: preparation of segments comprising the sequence of a cytotoxic 26-peptide analogue. J ournal of Organic Chemistry, 47: 3258-3261.

37. Mihara $\mathrm{H}$, Chmielewski J A \& Kaiser ET (1993). Synthesis of the 60 amino acid homeo domain and smaller fragments of the Drosophila gene regulatory protein Antennapedia by a segment synthesiscondensation approach. J ournal of Organic Chemistry, 58: 2209-2215.

38. Cerovsky V \& Bordusa F (2000). Proteasecatalysed fragment condensation via substrate mimetic strategy: a useful combination of solid-phase peptide synthesis with enzymatic methods. J ournal of Peptide Research (in press).

39. Cerovsky V \& J akubke H-D (1994). Enzymatic approach to the synthesis of taurine-containing peptides. International
J ournal of Peptide and Protein Research, 44: 466-471.

40. Schuster M, Munoz B, Paulson J C \& Wong C-H (1994). Papain-catalyzed synthesis of peptide isosteres. Tetrahedron Letters, 34: 1247-1250.

41. Bordusa F, Dahl C, J akubke H-D, Burger K $\&$ Koksch B (1999). Synthesis of $\alpha$-fluoroalkyl substituted peptides via enzymatic fragment condensation. Tetrahedron: Asymmetry, 10: 307-313.

42. Gutman $A L$, Meyer $E$, Yue $X \&$ Abell $C$ (1992). Enzymatic formation of lactams in organic solvents. Tetrahedron Letters, 33 : 3943-3946.

43. Quiros M, Sanchez VM, Brieva R, Rebolledo F \& Gotor V (1993). Lipasecatalyzed synthesis of optically active amides in organic media. Tetrahedron: Asymmetry, 4: 1105-1112.

44. Puertas S, Rebolledo F \& Gotor V (1995). Selective ammonolysis and aminolysis of dimethyl succinate. Synthesis of optically active $\mathrm{N}$-alkylsuccinimides. Tetrahedron, 51: 1495-1502.
45. Hoppe D (1998). In: Rehm HJ \& Reed G (Editors), Biotechnology. 2nd edn. Vol. 8a. Wiley-VCH, Weinheim, 262-267.

46. Günther R \& Bordusa F (1999). Substrate mimetic-mediated protease catalysis: A novel enzymatic approach to the synthesis of carboxylic acid amides. Chemistry A European J ournal, 6: 463-467.

47. Günther R, Stein A \& Bordusa F (2000). Investigations on the enzyme specificity of clostripain: A new efficient biocatalyst for the synthesis of peptide isosteres. J ournal of Organic Chemistry (in press).

48. Ullmann D \& J akubke H-D (1994). The specificity of clostripain from Clostridium histolyticum mapping the $S^{\prime}$ subsites via acyl transfer to amino acid amides and peptides. European J ournal of Biochemistry, 223: 865-872.

49. Bordusa $F$, Ullmann $D \&$ J akubke H-D (1997). Peptide synthesis from N- to Cterminus: an advantageous strategy using protease catalysis. Angewandte Chemie International Edition in English, 36: 10991101. 